\title{
Association between employer's knowledge and attitude towards smoking cessation and voluntary promotion in workplace: a survey study
}

Man Ping Wang ${ }^{1 *}$, William Ho Cheung Li ${ }^{1}$, Yi Nam Suen ${ }^{2}$, Ka Ching Cheung ${ }^{3}$, Oi Sze Lau ${ }^{4}$, Tai Hing Lam ${ }^{5}$ and Sophia Siu Chee Chan ${ }^{1}$

\begin{abstract}
Background: Workplace smoking cessation (SC) intervention is effective in increasing quit rate but little was known about the factors associated with voluntary SC promotion. Comprehensive smoke-free legislation, including banning smoking in all indoor area of workplaces, has been enforced in Hong Kong. This survey investigated the prevalence of company's compliance with smoke-free legislation and examined the relation between voluntary SC promotion in workplace and employer's knowledge of and attitude towards smoking and SC.

Methods: Half $(50.3 \%, n=292)$ of a convenience sample of companies completed a self-administered questionnaire on company's voluntary SC promotion in the workplace. Factors investigated included company's characteristics (size, type, and number of smoking employees); employers' knowledge of smoking, second-hand smoke and SC effects on health; perceived responsibility in assisting employees to quit smoking and smoking prohibition in workplace (smoke free policy). Logistic regression yielded adjusted odds ratio (aOR) for voluntary SC promotion.

Results: A notable proportion of companies (14.7\%) showed non-compliance with the smoke free workplace ordinance and only $10 \%$ voluntarily promoted SC. Perceived greater negative impact of smoking on the company (adjusted odds ratio[aOR] 1.94, 95\% confidence interval [Cl] 1.18-3.20) and better knowledge of smoking (aOR 1.40, $95 \% \mathrm{Cl}$ 1.00-1.94) were associated with voluntary SC promotion. Positive but non-significant associations were observed between perceived responsibility of assisting employees to quit, workplace smoke free policy and voluntary SC promotion. Company characteristics were generally not associated with voluntary SC promotion except white collar companies were less likely to promote SC (aOR 0.26, 95\% Cl 0.08-0.85).

Conclusions: This is the first survey on company's SC promotion in the Chinese population. A notable proportion of companies was not compliant with the smoke-free workplace ordinance. Employers with a higher level of knowledge and perceived impact of smoking on companies and from blue-collar companies were more likely to promote SC in workplace. The findings inform future workplace intervention design and policy.
\end{abstract}

Trial registration: The study was retrospectively registered at ClinicalTrials.gov (NCT02179424) dated 27 June 2014.

Keywords: Voluntary, Smoking cessation, Workplace, Chinese, Company

\footnotetext{
* Correspondence: mpwang@hku.hk

${ }^{1}$ School of Nursing, The University of Hong Kong, Hong Kong, SAR, China

Full list of author information is available at the end of the article
} 


\section{Background}

Smoke-free workplace policy is effective in reducing cigarette consumption, increasing quit rate, strengthening current tobacco control initiatives and protecting non-smoking employees from secondhand smoke (SHS) exposure [1]. However, the adoption is inconsistently prevalent in Western countries, ranging from 20\% in Greece to $54 \%$ in the US and $88 \%$ in the UK $[2,3]$. Similar study is scarce in Asian countries. One study has shown that less than half of the companies in Taiwan adopted smoke-free policy [4]. Regarding the low adoption rate, employers expressed their concerns on the lack of perceived responsibility for maintaining a smoke-free workplace, the insufficient knowledge on the impact of smoking on the company and employees, and the worries about undermining employee's morale and customer's satisfaction [5].

Previous study has found that non-smoking employers with positive attitude towards health and higher level of perceived responsibility were more likely to promote SC in workplace voluntarily [2]. Particularly, Chinese employers are less likely to consider assisting employees to quit smoking as their responsibility when compared with their western counterparts [6]. Such difference might be associated with the difference in the progress of tobacco control and smoke-free legislation, social norm of smoking, and attitudes and knowledge of employers on tobacco control in the workplace.

Hong Kong, as the most urbanised and westernised city in China, its smoking prevalence is amongst the lowest in the world (10.5\% in 2015) as various tobacco control measures have been enforced since 1982 [7]. The measures include imposing heavy tobacco tax $(70 \%$ of the retail price), banning smoking in most indoor and public places, completely banning tobacco advertisement, enlarging the pictorial warnings $(85 \%$ of the cigarette pack) and providing free SC services $[7,8]$.

In the formative component of a workplace SC project organised by Lok Sin Tong Benevolent Society, Kowloon (LST) commissioned by the Tobacco Control Office of Department of Health (Hong Kong SAR), we surveyed on company's characteristics and employer's knowledge, attitude and practice towards SC promotion. This study investigated the prevalence of company's compliance with smoke-free workplace ordinance and the relation between voluntary workplace SC promotion and employer's knowledge and attitude towards smoking and SC.

\section{Methods}

\section{Study design}

This cross-sectional survey was conducted in 2012. A self-administered questionnaire in Chinese was mailed to 580 companies which were selected from the list of the Caring Company Scheme 2012 organised by the
Hong Kong Council of Social Services (largest database of companies in Hong Kong). The questionnaire was required to be completed by adult (aged $\geq 18$ ) staff who was at managerial or above level including supervisors, managers and employers (hereafter as "employers").

\section{Measurements}

The questionnaire collected information on (1) company's characteristics including size, industry type and the number of smoking employees and (2) employer's knowledge, attitude and practice (KAP) in SC promotion. Companies size was classified into small ( $\leq 10$ employees), medium (11-100) and large $(\geq 100)$ by the number of employees. Company's industry type was categorised as bluecollar (construction, transportation food/restaurants \& property management), white-collar (insurance, finance/ bank, education \& information technology) or others (service, e.g., charity \& hospital). Employer's knowledge in SC promotion was assessed through seven items concerning the positive/negative consequences of $\mathrm{SC}$, the use of nicotine replacement therapy (NRT) and SHS. The items were regarded as most commonly misunderstood concept of smoking, cessation and SHS, generated by a panel of experts in the research team based on their substantial SC promotion experience. Similar items have been used in previous studies to test the knowledge of the personnel who engaged in SC promotion programme [9, 10]. Employers rated the items on a 4-point Likert scale ranging from 1 (strongly agree) to 4 (strongly disagree) and were considered as having a correct response if he agreed/ strongly agreed to a correct statement or disagreed/ strongly disagreed with an incorrect statement. Correct responses to these seven items were summed to derive a score of 0-7 in which higher scores indicated a higher level of knowledge. Two sub-scales were designed by the authors to assess employer's attitude towards SC promotion, that including their (1) perceived responsibility towards $\mathrm{SC}$ promotion and smoke-free policy in the workplace and (2) perceived impact of smoking on the company. The former was measured using a dichotomous question: "Whether employers have the responsibility to assist their employees to quit smoking?" (yes or no). The latter was measured by self-rating their perception of how smoking impact on company's productivity, image, working environment, environment outside the workplace and consumer perceived quality of service, using a 4-point Likert scale ranging from 1 (no impact) to 4 (severe impact). The scores of 3 or above (somewhat or severe impact) were categorized as "have perceived the negative impact of smoking on the company". Employer's practice in SC promotion was assessed by a set of questions related to any voluntary SC promotion in the past 12 months reported by the employers. The promotion could be in any means to promote $\mathrm{SC}$ and assist smoking staff to quit, ranging 
from disseminating information of the available SC services to offering incentives and/or interventions for cessation. Meanwhile, adoption of smoke-free policy in workplace was indicated by four levels of smoking prohibition in the workplace: "very strict", "strict", "less strict" and "not strict at all".

\section{Statistical analysis}

All analyses were performed using Stata version 13.0. Logistic regression was used to yield adjusted odds ratios (aOR) for voluntary SC promotion in relation to company size, company type, smoke-free policy, employers' perceived impact of smoking on the company, knowledge of smoking, SHS and perceived responsibility to assist employees to quit smoking. A $p$-value $<0.05$ denoted statistical significance.

\section{Results}

A total of 292 (50.3\% of 580 companies) completed and returned the valid questionnaires for data analysis. Companies of different sizes were included equally: small (35.6\%), medium (30.1\%) and large (34.3\%) (Table 1) and classified as blue-collar (32.1\%), white-collar (28.2\%) and others (39.7\%). A notable proportion of companies (14.7\%) showed non-compliance with the smoke-free ordinance in workplace. More than half (52.4\%) reported having smoking employees in the company, but only one-fourth (24.1\%) agreed that they were responsible for assisting employees to quit smoking. Among a few $(10.0 \%)$ that had ever promoted SC voluntarily in workplace, most delivered SC messages to their employees via posters, notices or leaflets. Many employers (about 90\%) were not aware of the negative consequences of smoking on mortality. Over one-third (37.7\%) thought that SHS is less harmful than outdoor air pollution and a half (47.8\%) were not aware that NRT can increase the quit rate.

Voluntary SC promotion was significantly and positively associated with employer's perceived impact of smoking on the company (adjusted odds ratio [aOR] 1.94, 95\% confidence interval [CI] 1.18-3.20) and knowledge of smoking and SHS (aOR 1.40, 95\% CI 1.00-1.94) and negatively associated with being white-collar company (aOR 0.26, 95\% CI 0.08-0.85) (Table 2). The perceived responsibility for assisting employees to quit smoking (aOR 1.65, 95\% CI 0.65-4.19) and company's smoke-free policy (aOR 1.25, 95\% CI 0.14-11.1) were positively but non-significantly associated with voluntary SC promotion. Company size was not associated with voluntary SC promotion.

\section{Discussion}

The present study is the first to examine the factors that associated with the adoption of voluntary workplace SC promotion in Chinese. In this study, a quarter of employers $(24.0 \%)$ perceived the responsibility to assist employees to quit smoking that is lower than the Western (39.0\%) and other Asian (38\%) countries [6]. The low adoption of voluntary SC promotion may be associated with employer's insufficient knowledge of smoking (i.e., most employers did not realise the high risk of tobaccoinduced mortality) and underestimation of the negative impact of smoking on the company, specifically in the aspect of productivity and customer satisfaction. Indeed, previous studies have reported the association between smoke-free workplace and improved business outcomes such as the number of customers or sales [11, 12]. While employer's roles in tobacco control and health promotion in workplace have been discussed in several company surveys in the US [2, 13], our finding suggested that the adoption can be predicted by employer's perceived impact of smoking on the company and their knowledge of smoking and SHS and future interventions shall target on these perspectives.

Workplace smoking has been comprehensively banned in Hong Kong since 2007, but we found that a remarkable proportion of companies (14.7\%) was not compliant with the legislation, that is similar to other countries (e.g. Ireland 14\%) [14]. The compliance with the smokefree workplace ordinance is a concern worldwide. The possible explanation on the low compliance in Hong Kong might be due to the deficiencies of the workplace smoke-free ordinance regarding coverage, surveillance and penalty. For instance, regular inspections or blitz operations conducted by the enforcement department only constitutes a small proportion of smoking offences in workplace. In 2014, only 8027 fixed penalty notices or summonses were issued among 29,000 inspections [15]. As the ordinance does not cover outdoor workplaces of the companies, nonsmoking employees and pedestrians are still exposed to SHS [16]. The situation may be even worse in Hong Kong due to its dense population and narrow pavements [17-19]. Banning smoking at outdoor workplaces and the entrances of buildings and shops (within 3 to $9 \mathrm{~m}$ ) should be considered [20, 21].

Implementation of smoke-free workplace policies may encourage employers to promote $\mathrm{SC}$ by denormalising smoking [22]. Establishing non-smoker hiring policies can be one of the measures contributing to motivate smokers to quit and healthier staff $[1,23]$, regardless the concerns about discrimination against smokers who are mostly in the lower socioeconomic group. Regarding the intervention to motivate quitting, most employers only adopted simple voluntary SC strategies such as posting notices of "smoking is prohibited". Other effective SC interventions such as providing incentives, time and psychological support for smoking employees to attend SC services are needed [24-29]. 
Table 1 Company's and employer's characteristics $(N=292)$

\begin{tabular}{|c|c|}
\hline Company's characteristics & $\mathrm{n}(\%)$ \\
\hline \multicolumn{2}{|l|}{ Company size } \\
\hline Small $(N=1-10)$ & $104(35.6)$ \\
\hline Medium $(N=11-100)$ & $88(30.1)$ \\
\hline Large $(N=100+)$ & $100(34.3)$ \\
\hline \multicolumn{2}{|l|}{ Company type ${ }^{a}$} \\
\hline Blue-collar & $92(31.5)$ \\
\hline White-collar & $81(27.7)$ \\
\hline Others & $119(40.8)$ \\
\hline Having smoking employee & $153(52.4)$ \\
\hline Having strict prohibition smokefree policy & $249(85.2)$ \\
\hline Employers perceived responsible for assisting employees to quit smoking & $70(24.0)$ \\
\hline Provision of assistance to help smoking staff to quit last year & $29(9.9)$ \\
\hline Messages (Poster, notice or leaflet) & $22(75.9)$ \\
\hline Health talks or enquiries & $7(24.1)$ \\
\hline Referral to smoking cessation service (Department of Health) & $5(17.2)$ \\
\hline \multicolumn{2}{|l|}{ Respondent's characteristics } \\
\hline Age (yrs.; mean $\pm S D$, range) & $37.4 \pm 10.9(18-85)$ \\
\hline \multicolumn{2}{|l|}{ Position } \\
\hline Employer (Owner of the company) & $56(19.2)$ \\
\hline Manager & $119(40.8)$ \\
\hline Supervisor & $117(40.1)$ \\
\hline Perceived impact of smoking on company $(0-5 \text {; mean } \pm S D)^{b}$ & $3.30 \pm 1.85$ \\
\hline Productivity & $151(55.7)$ \\
\hline Corporate image & $195(70.9)$ \\
\hline Work environment & $220(79.4)$ \\
\hline Environment outside workplace & $215(78.8)$ \\
\hline Customer's evaluation of service quality & $182(67.4)$ \\
\hline Knowledge of smoking and second-hand smoke $(0-7 \text {; mean } \pm S D)^{c}$ & $3.42 \pm 1.67$ \\
\hline Quitting is too late if smoked for years & $212(76.3)$ \\
\hline Quitting may harm health of elderly smokers and quitting is not necessary & $219(79.4)$ \\
\hline Using low-tar cigarettes is a safe alternative to quitting & $200(72.7)$ \\
\hline Nicotine gum and patches increase quit rate & $132(47.8)$ \\
\hline 1 out of 20 smokers will be killed by smoking & $34(12.4)$ \\
\hline Preventing children and adolescent smoking is the most important way to reduce smoking-attributable mortality & $29(10.5)$ \\
\hline Second-hand smoke is less harmful than outdoor air pollution & $172(62.3)$ \\
\hline
\end{tabular}

${ }^{a}$ Top 5 industries (\%), in term of the number of companies involved in this study, were Finance/ Bank (11.2\%), Information Technology (9.1\%), Property Management (8.4\%), Food service/ Restaurants (5.6\%), Education (4.9\%)

${ }^{b}$ Respondent scored 1 point if he/she perceived "somewhat impact" or "severe impact" on the 5 items listed below; the total score ranged from 0 to 5

${ }^{c}$ Respondent scored 1 point if he/she gave a correct answer to each of the listed items; the total score ranged from 0 to 7

Contrary to the observation in the US and Taiwan, large and blue-collar companies in the present study were more likely to promote SC $[2,4,13]$. Large companies are led by written regulations and more likely to comply with the smoke-free workplace ordinance while small/medium companies were more likely to rely on informal communication and to respect individual freedom of smoking [2]. Our finding that SC promotion was more likely to happen in blue collar companies might be due to the higher smoking prevalence in this group in Hong Kong. Notably, the need for SC promotion in the white-collar companies may be neglected. The result suggested that the design of SC promotion activities should consider the company size and type. 
Table 2 Association between company's characteristics, employer's knowledge and attitude and voluntary smoking cessation (SC) promotion in workplace

\begin{tabular}{|c|c|c|c|}
\hline & & Voluntary SC promo & \\
\hline & $\mathrm{n}(\%) /$ mean $\pm \mathrm{SD}$ & Crude OR (95\% Cl) & Adjusted OR $(95 \% \mathrm{Cl})^{\mathrm{a}}$ \\
\hline Knowledge of smoking & $4.39 \pm 1.20$ & $1.59(1.15-2.21)^{* *}$ & $1.40(1.00-1.94)^{*}$ \\
\hline Perceived impact & $4.62 \pm 0.82$ & $2.17(1.34-3.49)^{* *}$ & $1.94(1.18-3.20)^{* *}$ \\
\hline Perceived responsibility & & & \\
\hline No & 8.2 & 1.00 & 1.00 \\
\hline Yes & 17.1 & $2.32(1.05-5.15)^{*}$ & $1.65(0.65-4.19)$ \\
\hline Smokefree policy & & & \\
\hline No & 5.6 & 1.00 & 1.00 \\
\hline Yes & 10.2 & $1.93(0.25-15.1)$ & $1.25(0.14-11.1)$ \\
\hline Company size & & & \\
\hline Small/Medium & 7.9 & 1.00 & 1.00 \\
\hline Large & 14.1 & $1.92(0.89-4.16)$ & $2.10(0.85-5.14)$ \\
\hline Company type & & & \\
\hline Blue collar & 18.7 & 1.00 & 1.00 \\
\hline White collar & 4.9 & $0.23(0.07-0.70)^{*}$ & $0.26(0.08-0.85)^{*}$ \\
\hline Others & 7.1 & $0.33(0.14-0.81)^{*}$ & $0.45(0.16-1.25)$ \\
\hline
\end{tabular}

$O R$ odds ratio, $\mathrm{Cl}$ confidence interval

${ }^{*} p<0.05,{ }^{* *} p<0.01$

autually adjusted for each other

This study has several limitations. First, the convenience sampling method may compromise the representativeness of our sample to the population. Specifically, it was likely that the employers who agreed to join our study were more aware of the smoking issues. Thus, the prevalence of smoke-free policy in the workplace might be overestimated. Second, the cross-sectional method limited the casual inference about the associations of employer's perceived responsibility for assisting employees to quit smoking and the enforcement of smoke-free policies in the company with employer's SC promotion. Finally, the study relied on self-reported data, which was subjected to response bias.

\section{Conclusions}

This study investigated company's SC promotion in the Chinese population. A notable proportion of companies was not compliant with the smoke-free workplace ordinance in Hong Kong. Employers with a higher level of knowledge and perceived impact of smoking on companies and from blue-collar companies were more likely to promote SC in workplace. The findings inform future workplace intervention design and policy.

\section{Abbreviation}

aOR: Adjusted odds ratio; Cl: Confidence interval; NRT: Nicotine replacement therapy; SC: Smoking cessation; SD: Standard deviation; SHS: Secondhand smoke

\section{Acknowledgements}

We would like to thank the participants of the company survey, Ms. Iris Wong, Dr. Jing Chen and Ms. Vivian Chan for project coordination.

\section{Funding}

This work was supported by the Lok Sin Tong Benevolent Society, Kowloon.

\section{Availability of data and materials}

All data generated or analysed during this study are included in this article.

\section{Authors' contributions}

WMP, LWHC, LOS, LTH and CSSC: contributed to the conception of the study. WMP, SYN, CKC: contributed significantly to analysis and manuscript preparation. LWHC, LOS, LTH and CSSC: contributed to revising the manuscript critically for important intellectual content. All authors read and approved the final manuscript.

Ethics approval and consent to participate

The study was approved by the Institutional Review Board of the University of Hong Kong and Hong Kong Authority Hong Kong West Cluster (UW-12-550). Written, informed consent was obtained from all participants enrolled in this study.

\section{Consent for publication}

Not applicable.

\section{Competing interests}

The authors declare that they have no competing interests.

\section{Publisher's Note}

Springer Nature remains neutral with regard to jurisdictional claims in published maps and institutional affiliations.

\section{Author details}

${ }^{1}$ School of Nursing, The University of Hong Kong, Hong Kong, SAR, China. ${ }^{2}$ Department of Psychiatry, The University of Hong Kong, Hong Kong, SAR, China. ${ }^{3}$ Department of Asian and Policy Studies, The Education University of 
Hong Kong, Hong Kong, SAR, China. ${ }^{4}$ The Lok Sin Tong Benevolent Society, Kowloon, Hong Kong, SAR, China. ${ }^{5}$ School of Public Health, the University of Hong Kong, Hong Kong, SAR, China.

Received: 28 August 2017 Accepted: 3 November 2017

Published online: 14 November 2017

\section{References}

1. McDaniel PA, Malone RE. Businesses' voluntary pro-health tobacco policies: a review and research agenda. Tob Control. 2012;21(1):66-72.

2. Emmons KM, Thompson B, McLerran $\mathrm{D}$, et al. The relationship between organizational characteristics and the adoption of workplace smoking policies. Health Educ Behav. 2000;27(4):483-501.

3. The Gallup Organisation, H. Flash Eurobarometer No 253 survey on tobacco. Analytical report. Hungary: The Gallup Organisation; 2009.

4. Wen CP, Hu SC, Huang SJ, Tsai SP, Cheng TY. Controlling cigarette smoking in the workplace in Taiwan: opportunities and challenges. J Public Health Policy. 2004;25(3-4):315-27.

5. Castellan RM, Chosewood LC, Trout D, et al. Promoting health and preventing disease and injury through workplace tobacco policies. In: Current intelligence bulletin 67. Morgantown: U.S. Department of Health and Human Services, Centers for Disease Control and Prevention, National Institute for Occupational Safety and Health; 2015.

6. Halpern MT, Taylor H. Employee and employer support for workplace-based smoking cessation: results from an international survey. J Occup Health. 2010:52(6):375-82.

7. Census and Statistics Department. Thematic Household Survey, Report No. 59: Pattern of Smoking. Available from: http://www.statistics.gov.hk/pub/ B11302592016XXXXB0100.pdf. Accessed 15 May 2016.

8. World Health Organization. WHO report on the global tobacco epidemic 2013. Geneva: World Health Organization; 2013.

9. Leung DY, Chan SS, Fu IC, Lam TH. Knowledge, attitudes and practices regarding smoking cessation among Chinese affiliates of women's organisations in Hong Kong. Health Soc Care Community. 2011;19(2):207-16.

10. Guo N. Knowledge, attitudes, practice (KAP) and organizational support on delivering smoking cessation services on Guangzhou health careprofessionals. In: HKU Theses Online (HKUTO). Pokfulam: The University of Hong Kong; 2007

11. McCaffrey M, Goodman PG, Kelleher K, Clancy L. Smoking, occupancy and staffing levels in a selection of Dublin pubs pre and post a national smoking ban, lessons for all. Ir J Med Sci. 2006;175(2):37-40.

12. Thomson G, Wilson N. One year of smokefree bars and restaurants in New Zealand: impacts and responses. BMC Public Health. 2006;6:64.

13. Hughes MC, Yette EM, Hannon PA, Harris JR, Tran NM, Reid TR. Promoting tobacco cessation via the workplace: opportunities for improvement. Tob Control. 2011;20(4):305-8.

14. Fong GT, Hyland A, Borland R, et al. Reductions in tobacco smoke pollution and increases in support for smoke-free public places following the implementation of comprehensive smoke-free workplace legislation in the Republic of Ireland: findings from the ITC Ireland/UK survey. Tob Control. 2006;15(Suppl 3):iii51-8.

15. Tobacco Control Office. TCO of DH committed to enforcing smoking ban (with photos). Available from: https://www.tco.gov.hk/tc_chi/infostation/ infostation 11032015.html. Accessed 11 Dec 2015.

16. Lai HK, Hedley AJ, Repace J, et al. Lung function and exposure to workplace second-hand smoke during exemptions from smoking ban legislation: an exposure-response relationship based on indoor PM2.5 and urinary cotinine levels. Thorax. 2011;66(7):615-23.

17. Ashley M, Saunders P, Mullard G, et al. Smoking intensity before and after introduction of the public place smoking ban in Scotland. Regul Toxicol Pharmacol. 2011;61(3 Suppl):S60-5.

18. Ho SY, Wang MP, Lo WS, et al. Comprehensive smoke-free legislation and displacement of smoking into the homes of young children in Hong Kong. Tob Control. 2010;19(2):129-33.

19. Kennedy RD, Behm I, Craig L, et al. Outdoor smoking behaviour and support for outdoor smoking restrictions before and after France's national smoking ban. Eur J Pub Health. 2012;22(Suppl 1):29-34

20. City of Toronto. Live Tobacco-Free - Legislation. Available from: https://www1. toronto.ca/wps/portal/contentonly?vgnextoid=0adb62ca69902410VgnVCM10 000071d60f89RCRD. Accessed 26 May 2015
21. Tobacco in Australia. Legislation to ban smoking in public spaces. Available from: http://www.tobaccoinaustralia.org.au/chapter-15smokefree-environment/15-7-legislation. Accessed 11 Dec 2015.

22. Fichtenberg CM, Glantz SA. Effect of smoke-free workplaces on smoking behaviour: systematic review. BMJ. 2002;325(7357):188.

23. Voigt K. Ethical concerns in tobacco control nonsmoker and "nonnicotine" hiring policies: the implications of employment restrictions for tobacco control. Am J Public Health. 2012;102(11):2013-8.

24. Fishwick D, Carroll C, McGregor M, et al. Smoking cessation in the workplace. Occup Med. 2013;63(8):526-36.

25. Kouvonen A, Kivimaki M, Oksanen T, et al. Implementation of workplace-based smoking cessation support activities and smoking cessation among employees: the Finnish public sector study. Am J Public Health. 2012;102(7):e56-62.

26. Terry PE, Seaverson EL, Staufacker MJ, Tanaka A. The effectiveness of a telephone-based tobacco cessation program offered as part of a worksite health promotion program. Popul Health Manag. 2011;14(3):117-25.

27. Stolz D, Scherr A, Seiffert B, et al. Predictors of success for smoking cessation at the workplace: a longitudinal study. Respiration. 2014;87(1):18-25.

28. Rongen A, Robroek SJ, van Lenthe FJ, Burdorf A. Workplace health promotion: a meta-analysis of effectiveness. Am J Prev Med. 2013;44(4):406-15.

29. Paul CL, McLennan J, Baxendale A, et al. Implementation of a personalized workplace smoking cessation programme. Occup Med. 2013;63(8):568-74

\section{Submit your next manuscript to BioMed Central and we will help you at every step:}

- We accept pre-submission inquiries

- Our selector tool helps you to find the most relevant journal

- We provide round the clock customer support

- Convenient online submission

- Thorough peer review

- Inclusion in PubMed and all major indexing services

- Maximum visibility for your research

Submit your manuscript at www.biomedcentral.com/submit
Biomed Central 